\title{
Analysis on the Current Situation and Trend of Core Technology of Energy Electric Vehicle
}

\author{
Shang Shang* \\ Naili Energy Development Co., Ltd. E-mail: shangs@sina.com
}

\begin{abstract}
Under the environment of advocating environmental protection and energy saving, the new energy electric vehicle technology has developed rapidly and become the research hotspot of the current international automobile industry. The new energy electric vehicle has obvious advantages in power, energy saving, environmental protection, driving experience, post-maintenance and so on. Its production process and efficiency are much higher than those of traditional fuel vehicles, which is the inevitable trend of the future development of the automobile industry and plays an important role in the overall sustainable development of the automobile industry. This paper mainly introduces the three core technologies, development status and future development trend of new energy electric vehicles.
\end{abstract}

Keywords: New Energy Vehicles; Core Technology; Hydrogen Fuel

\section{New energy electric vehicle the- ory overview and development sta- tus analysis}

\subsection{Review of new energy electric vehicle theory}

New energy vehicles refer to all other energy vehicles except gasoline and diesel engines. According to the definition announced by the National Development and Reform Commission of the People's Republic of China, new energy vehicles refer to vehicles with advanced technical principles, new technologies and new structures, which use unconventional vehicle fuels as power sources (or conventional vehicle fuels and new vehicle-mounted power devices).

New energy vehicles can be divided into pure electric vehicles, plug-in hybrid vehicles, conventional hybrid vehicles and other new energy vehicles (including extended-range electric vehicles, hydrogen fuel vehicles, solar energy vehicles, etc.) according to the scope of use.

\subsection{Advantages and problems of new energy electric vehicles}

\subsubsection{Advantages of new energy electric ve- hicles}

(1) Energy saving, environmental protection and good economy

At present, most of the new energy vehicles use electricity as power, while a few use hydrogen energy and solar energy. Electric vehicles do not produce tail gas and have no pollution. The tail gas of hydrogen energy vehicles is water, which has no pollution to the environment, and has the characteristics of low price and zero emission.

(2) High efficiency, high comfort and low noise

New energy vehicles are more efficient, without $\mathrm{NVH}$ and frustration when shifting gears, and the whole driving process is relatively smooth, comfortable and

Copyright (C) 2020 Shang Shang

doi: 10.18282/pef.v9i2.1367

This is an open-access article distributed under the terms of the Creative Commons Attribution Non-Commercial License

(http://creativecommons.org/licenses/by-nc/4.0/), which permits unrestricted non-commercial use, distribution, and reproduction in any medium,

provided the original work is properly cited. 
low in noise.

\subsubsection{Problems of new energy electric vehi- cles}

(1) The cruising range is short, and it is inconvenient to charge and change electricity

The cruising range of new energy vehicles is restricted by battery technology and charging environment. The emphasis of battery technology lies in the breakthrough of battery energy density or finding more suitable and stable materials. At the same time, considering the charging safety, the overall charging speed of new energy vehicles has to be reduced. Overall, the average charging process is $2-3 \mathrm{~h}$, which is far less than that of traditional fuel vehicles.

(2) There are potential safety hazards and high maintenance costs

The biggest potential safety hazard of new energy vehicles is batteries. Internal short circuit (such as local temperature rise, impurity/burr, dendrite, diaphragm defect, diaphragm deformation) and external reasons (mainly puncture, squeeze or external fire) will cause serious safety problems.

\section{Research on the development trend of core technologies of new energy electric vehicles}

Different from traditional fuel vehicles, the core of new energy electric vehicles is three technologies, namely, driving motor, power battery and battery management technology.

\subsection{Drive motor technology}

\subsubsection{Types of motors}

At present, the driving motors mainly include DC motor, induction motor, switched reluctance motor, brushless DC motor and permanent magnet synchronous motor. Each type of motor has its own characteristics. In terms of speed, switched reluctance motor is the highest, followed by AC asynchronous motor, and DC motor is the lowest, but permanent magnet synchronous motor has a large speed range; From the perspective of performance reliability and structural firmness, switched reluctance motor and AC asynchronous motor have the strongest reliability, followed by permanent magnet synchronous motor; In terms of mass and volume, switched reluctance motor has small mass and volume, while DC motor has large mass and volume.

\subsubsection{Development trend of driving motor}

According to the current technical development, the main trends of driving motors are:

(1) Highly integration. Specifically, the automotive electrical control system is gradually highly integrated, and the controllers of motor, engine control, whole vehicle and low-voltage DC-DC converter are integrated in different ways.

(2). Digitization. With the use of high-speed and high-performance microprocessors and user-oriented visual programming, high-performance control algorithms and complex control theories can be realized.

(3) The improvement of motor power and power density. The motor power has increased from several kilowatts to tens of kilowatts or even higher, and the efficiency has been greatly improved. The motor is getting smaller and smaller, and the power density is constantly increasing.

(4) The motor feedback braking efficiency and running speed are improved. One of the characteristics of hybrid electromechanical integration technology is feedback braking. Using efficient feedback braking motor and special power management and speed regulation system can make the motor handle various working conditions, thus making electric vehicles more energy-saving and extending driving mileage.

\subsection{Power battery technology}

In recent years, the demand for power batteries in China has experienced explosive growth. In 2019, the installed capacity of power batteries reached 62.37 $\mathrm{GW} \cdot \mathrm{h}$, an increase of 9.5\% compared with 2018. Power battery is the energy and power source of new energy vehicles. The cruising range of electric vehicles is limited by batteries.

\subsubsection{Types of batteries}

At present, power batteries can be divided into three systems, namely lithium iron phosphate battery, ternary lithium battery and lithium iron manganate battery. Among them, lithium iron manganate batteries and lithium iron phosphate batteries are widely used in electric buses because of their reliable stability and low price. At the same time. The development of power battery technology also has a critical impact on NEV products.

In addition to all-solid-state lithium batteries, other 
types of batteries, such as lead-acid batteries, nickel-hydrogen batteries, lithium-ion batteries and solar batteries, have their own characteristics. At present, the technical route trend of power battery is lithium iron phosphate $\rightarrow$ ternary lithium $\rightarrow$ solid state battery. In order to achieve higher energy density in the future, it is necessary to change to the technical system of solid-state batteries. The system of solid electrode+solid electrolyte has high energy density, and the electrolyte has no fluidity. It is easy to form a high voltage monomer through internal series connection, which is expected to reach $500 \mathrm{~W} \mathrm{~h} / \mathrm{kg}$. At the same time, it has high safety and does not cause electrolyte combustion.

\subsubsection{Wireless charging}

The essence of wireless power transmission is to realize wireless power supply from the primary side to the secondary side through the coupling of physical fields such as magnetic field, electric field, electromagnetic wave, etc. In the field of wireless charging technology of pure electric vehicles, according to different transmission mechanisms, it can be divided into magnetic field coupling type (magnetic field coupling type is divided into magnetic resonance type and magnetic induction type), electric field coupling type and microwave radiation type.

At present, the mainstream wireless charging technologies are mainly magnetic resonance and magnetic induction. Qualcomm and Wi Tricity adopt the business model of technology licensing, while the other companies mainly sell wireless charging equipment. The existing wireless charging technical standards mainly include AirFuel and Qi, and the future charging technical standards will be unified. Wireless charging technology is also facing multi-dimensional bottlenecks. Apart from the main cost problem, the development of wireless charging technology is hindered by the inconsistent charging standards, charging efficiency and charging distance restrictions.

\subsubsection{Electricity exchange technology}

Automobile power exchange technology is a technology to replace new power batteries by removing power batteries that have been attenuated or consumed by new energy vehicles from vehicles. Compared with the traditional charging mode, the advantages of the switching mode are that it can shorten the replenishment time, improve the efficiency, prolong the battery life, and eliminate the short cruising range. The technology of power exchange is mainly divided into single power exchange and quick battery exchange.

Single power exchange refers to replacing the power battery of a new energy vehicle at one time, so that the vehicle has enough battery capacity to continue driving and increase the cruising range. The problem is that the capacity of the replaced new battery is still the same as that of the previous power battery, and the cruising range of the car has not been actually increased.

Multiple battery replacement technology (quick battery replacement technology) means that the power battery can be replaced in a short time by using a specific device at any time of new energy vehicles, thus increasing the cruising range of new energy vehicles, which is similar to the refueling process of traditional fuel vehicles. Multiple power exchange technology is the main development direction and trend of power exchange technology in the future.

\subsection{Battery management technology}

\subsubsection{Basic functions of battery management system}

Battery management system (BMS) is an important link between electric vehicles and on-board power batteries. It can detect the running state (charge state, health state and function state) of batteries quickly and in real time, and transmit real-time information to subsystems. By effectively managing the battery, the battery can be maintained in the best working state.

\subsubsection{Structure of battery management sys- tem}

The battery management system consists of a central control unit and a local control unit. The central control unit is responsible for data processing, SOC calculation, logic judgment and corresponding control. The local intelligent acquisition unit is responsible for battery information and battery state detection. The CAN bus communication is used to complete data transmission and realize centralized management and distributed control of the system. At the same time, it is convenient to distribute the batteries, so as to reduce the wiring harness and improve the reliability of the system.

\section{Conclusion}

New energy electric vehicle is the inevitable trend 
of the future development of automobile industry. At present, the development trend of the three core technologies is mainly reflected in three aspects: (1) The driving motor is the most direct power device for driving vehicles. The motor technology represented by permanent magnet synchronous motor and hub motor has significantly improved the performance and comfort, and made the acceptance and popularity of new energy electric vehicles increase. The development of core technologies around permanent magnet of motor, integration and integration of motor drive system, integration and digitalization of motor control has become a research hotspot at home and abroad. (2) Power battery technology is the most important and competitive core technology of new energy electric vehicles. Wireless charging and changing technology can break the limitation of charging in time and space, greatly improve the charging efficiency and solve the charging problem. (3) Battery management technology, as an important link between electric vehicles and on-board power batteries, can improve the use efficiency of batteries, and achieve the goals of increasing cruising range, prolonging battery life and improving the reliability of battery packs.

New energy electric vehicles have a good development prospect all over the world. China should actively develop the core technologies of new energy electric vehicles, so as to promote the further development of new energy electric vehicles in China.

\section{References}

1. Gao J, Miao Z, Li W, et al. Investigation on influencing factors of acceptance of new energy electric vehicles (in Chinese). Management Observation 2020; (25): 14-17.

2. Gao X, Zhou C. Study on the implementation effect of new energy vehicle consumption incentive policy (in Chinese). Henan Science 2020; 38(8): 13151323.

3. Lu D, Guo H. Economic feasibility analysis of using lithium hydride or magnesium hydride as electric vehicle energy (in Chinese). Scientific and Technological Innovation and Productivity 2020; (8): 4143+48.

4. Jiang Y. Discussion on functional safety technology of "three power systems" based on new energy vehicles (in Chinese). Auto Time 2020; (16): 67-68. 